\title{
Artelogie
}

Recherche sur les arts, le patrimoine et la littérature de l'Amérique latine

5 | 2013

Femmes créatrices en Amérique latine : le défi de synthétiser sans singulariser

\section{Del naufragio al cautiverio: Pintores europeos, mujeres chilenas e indios Mapuche a mediados del siglo XIX}

Josefina De La Maza

\section{(2) OpenEdition \\ Journals}

Edición electrónica

URL: https://journals.openedition.org/artelogie/5208

DOI: $10.4000 /$ artelogie.5208

ISSN: 2115-6395

\section{Editor}

Association ESCAL

Referencia electrónica

Josefina De La Maza, «Del naufragio al cautiverio: Pintores europeos, mujeres chilenas e indios Mapuche a mediados del siglo XIX», Artelogie [En línea], 5 | 2013, Publicado el 16 octubre 2013, consultado el 20 diciembre 2021. URL: http://journals.openedition.org/artelogie/5208 ; DOI: https:// doi.org/10.4000/artelogie.5208

Este documento fue generado automáticamente el 20 diciembre 2021.

Association ESCAL 


\title{
Del naufragio al cautiverio: Pintores europeos, mujeres chilenas e indios Mapuche a mediados del siglo XIX
}

\author{
Josefina De La Maza
}

Señoritas delicadas, criadas en los colegios de
Santiago, han sido víctimas de las brutalidades
que no están en la naturaleza humana; aquellos
cuerpos ultrajados, han sido como último acto del
drama horrible, ensartados en palos que han
desgarrado las entrañas de las víctimas, vivas
aun...!!!
La Tribuna, Santiago 5 de noviembre, 1849

El naufragio del bergantín “Joven Daniel” en agosto de 1849 impactó profundamente a la sociedad chilena. A la conmoción causada por el naufragio - riesgo conocido para quienes se trasladaban por vía marítima durante los meses del invierno chileno - se sumaba el destino final que habría tenido la tripulación y los pasajeros. De acuerdo a la prensa de la época nadie había muerto en alta mar, pero una vez en tierra firme a la espera de asistencia habrían sido asesinados por los indios del sur de Chile. Esta información, errónea y teñida de sensacionalismo, fue continuamente reiterada en distintos centros urbanos del país a través de diversos medios escritos. Fue tal la fuerza de este destino ficticio y alternativo, en el que las mujeres a bordo del "Joven Daniel" habrían tenido un dramático protagonismo, que la sola mención de "indios salvajes" rápidamente complejizó las ya tensas relaciones entre el Estado chileno y grupos indígenas. No es de extrañar, entonces, que este episodio haya llamado también la atención de artistas y escritores, quienes vieron en la fantasía del rapto, violación y posterior muerte de las mujeres chilenas, un tema a ser utilizado. Uno de esos artistas era Raymond Quinsac Monvoisin (1790-1870), pintor académico francés que durante la década de 1840 fijó domicilio en Chile. 
2 Monvoisin llegó al país en el año 1843 y las obras que trajo consigo desde Francia constituyeron la primera exposición de "arte académico" en la ciudad de Santiago. Para muchos espectadores de la época, la llegada del artista francés a Chile significó el comienzo de una nueva era de "buen gusto y arte moderno"1. Después de una primera temporada en el país que se extendería hasta 1845, el artista se volvió a instalar en el valle central entre 1848 y 1857 (además de Chile, Monvoisin estuvo durante breves temporadas en Argentina, Perú y Brasil). Dedicando la mayor parte de su tiempo a retratar a la clase alta de la capital, buena parte de sus obras "chilenas" terminó siendo irregular y defectuosa en términos formales. A pesar de sus faltas, el artista nunca ha perdido su lugar en el canon artístico chileno ${ }^{2}$.

Fig.1 - Raymond Quinsac Monvoisin. Naufragio del joven Daniel, 1859, óleo sobre tela, 177 x 130,5 cm

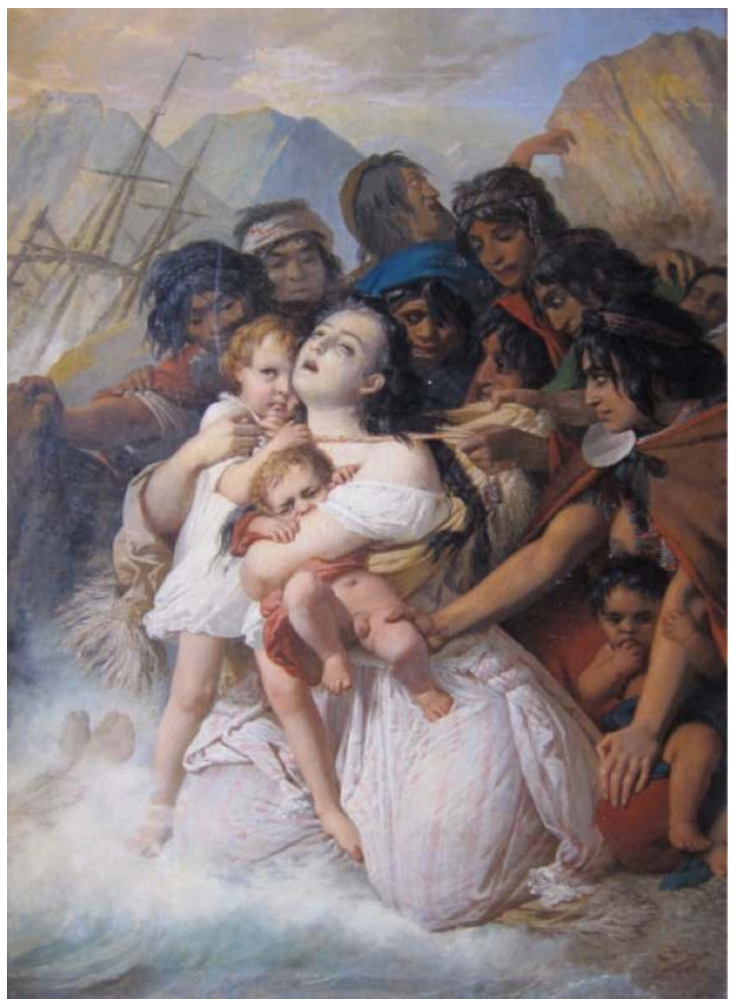

Colección: MOBAT, Talca. Fotografía: Josefina de la Maza 
Fig. 2 - Raymond Quinsac Monvoisin. Elisa Bravo Jaramillo de Bañados, mujer del Cacique, 1859, óleo sobre tela, $178 \times 130,5 \mathrm{~cm}$

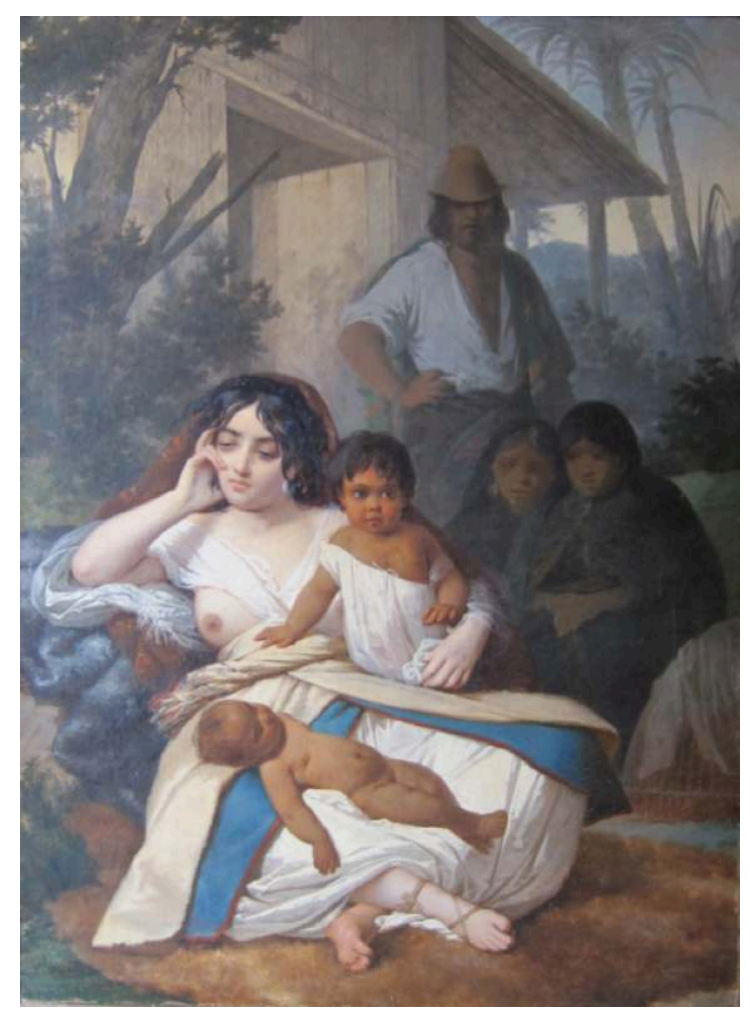

Colección: MOBAT, Talca. Fotografía: Josefina de la Maza

Recordando los eventos de 1849, Monvoisin pintó diez años más tarde y a su vuelta definitiva a París, El naufragio del joven Daniel y Elisa Bravo Jaramillo de Bañados, mujer del cacique (ambas de 1859 - figs. 1 y 2). Estas obras rápidamente se convirtieron - gracias al poder del libro y de la imprenta - en las imágenes más conocidas asociadas a la tragedia. El díptico cuenta la historia de la que habría sido la única sobreviviente del naufragio: Elisa Bravo Jaramillo de Bañados. Basándose en la ficción recogida por la prensa, ellas narran el primer encuentro entre la mujer y los indígenas y su posterior vida como cautiva ${ }^{3}$. La estructura de ambas obras presenta el proceso de corrupción del cuerpo "civilizado" de Elisa Bravo y dan cuenta, de manera soterrada, de los diversos niveles y alcances de la imaginación imperial de la época - imaginación proyectada tanto por el artista metropolitano como por el público chileno de mediados del siglo XIX.

4 Si consideramos el tema, la distancia temporal entre los eventos y la posterior elaboración del artista, y los alcances políticos e ideológicos de este díptico, es curioso que estas obras no hayan alcanzado una mayor atención crítica. Poco se conoce, por ejemplo, de la "vida social" de estas obras. En todo caso, es posible argumentar - a partir de las reflexiones tempranas de Benjamín Vicuña Mackenna - que después de su exhibición en el salón parisino de 1859 el artista habría mantenido las obras en su poder hasta su muerte (VICUÑA MACKENNA, 1876, p. 82). Con posterioridad, ellas habrían sido adquiridas por Adriana Cousiño Goyenechea (18; ?-1948), quién habría gestionado su donación, en 1930, al Museo Nacional de Bellas Artes. Los CousiñoGoyenechea fueron una de las familias más ricas de la segunda mitad del siglo XIX chileno; la familia era dueña de casi todas las obras de gran formato de Monvoisin, 
obras que habían sido adquiridas en el año 1843 al finalizar la exposición de sus obras en los salones de la exUniversidad Real de San Felipe. La adquisición del díptico por parte de Adriana Cousiño es reveladora en relación a los vínculos que la familia tenía con el artista. Seis años después de la donación de Cousiño al Museo Nacional de Bellas Artes, las pinturas fueron transferidas al Museo O'Higginiano y de Bellas Artes de Talca donde se encuentran hasta el día de hoy.

5 Si bien no existen estudios acabados sobre el díptico, este ha sido generalmente comentado al interior de historias del arte chileno poniendo atención acerca de su "extravagancia", reforzando los mismos prejuicios de corte racial y de género que informan a las pinturas y enfatizando el carácter "romántico" de las obras. De hecho, se podría argumentar que el "romanticismo" de Monvoisin se define en términos pictóricos a partir de este díptico. Para Antonio Romera, por ejemplo, Monvoisin fue capaz de "liberarse románticamente" a sí mismo de las ataduras de la academia a través del "exotismo" americano (Romera, 1950, pp.120-122). Si uno presta atención a afirmaciones como esta, el romanticismo de Monvoisin generalmente se asocia de manera inmediata a una noción simplista de orientalismo: la experiencia romántica se completa cuando el artista encuentra un tema dramático y pintoresco como el de Elisa Bravo; su espíritu aventurero es entonces premiado con un tema que revela el carácter exótico de su destino transoceánico, encarnado en este caso por el pueblo Mapuche, pueblo que desde la época de la conquista había resistido violentamente a la dominación española ${ }^{4}$. Estas ideas han prevalecido por décadas en textos académicos y catálogos, aun cuando las fuentes primarias del periodo han probado cuán errada es esta afirmación ${ }^{5}$. De hecho, a comienzos de la década de 1840 y después de un largo periodo en París, el artista decidió por razones profesionales y personales buscar una nueva red de clientes en el extranjero que revitalizara su práctica artística, la que se había visto debilitada tras una serie de desencuentros con su mecenas más importantes (DE LA MAZA, 2011, pp.36-39). Independiente del deseo de ver nuevas tierras, las urgencias de Monvoisin apuntaban, más bien, a cuestiones económicas y sociales.

Si bien el artista viajó por un largo periodo de tiempo a través de Sudamérica, sus viajes estuvieron permeados por un complejo conjunto de prejuicios sobre el continente. Medianamente solapados al retratar a las elites de distintos países sudamericanos, estos prejuicios tomaron forma en un pequeño grupo de obras que presentan una mirada particularmente significativa acerca del Cono Sur. Soldado de la guardia de Rosas (1840s), Gaucho federal (1842), Los refugiados del Paraguay (1842 y 1859), Caupolicán prisionero de los españoles (1859) y, sobre todo, El naufragio del joven Daniel y Elisa Bravo..., presentaban temas y sujetos argentinos, paraguayos y chilenos con ojos metropolitanos ${ }^{6}$. Incluso al interior de este pequeño grupo de obras, el díptico sobre Elisa Bravo es una nota disonante. Pintado después de su experiencia sudamericana en 1859, estas son las únicas obras que presentan la interacción de una mujer blanca con indígenas americanos. No se sabe si este díptico respondió al encargo de un mecenas; probablemente, sería más acertado considerar que Monvoisin concibió ambas obras como una estrategia de reinserción en el contexto artístico parisino a través de su exposición en el salón, transformando de manera dramática un naufragio en una historia de barbarismo colonial. Usando como punto de partida el tropo de la cautiva, un tema conocido desde la época de la colonia, el díptico validó preceptos racistas, transformó a los indios en "otros" exóticos y orientalizados y puso atención a los márgenes simbólicos y materiales en los que residían las mujeres (chilenas) en el espacio de la frontera; espacio que dividía a la "sociedad chilena" de un "mundo 
bárbaro y anárquico". Las pinturas, y especialmente la circulación de las mismas a través de grabados, contribuyó a consolidar una serie de juicios sobre la Araucanía como una región indomable que debía ser definitivamente conquistada por el estado chileno. El "destino cautivo" de Elisa Bravo en las pinturas de Monvoisin contribuyó a reforzar ese significado.

7 Este artículo analizará el díptico de Elisa Bravo a la luz de la representación de la mujer al interior de discursos coloniales y de expansión imperial. Examinando El naufragio del joven Daniel y Elisa Bravo... a través del tropo de la cautiva, este artículo reconstruirá el lugar de la mujer decimonónica y la instrumentalización de lo femenino entre redes artísticas y simbólicas, entre Chile y Sudamérica y entre Sudamérica y Europa.

\section{De la pintura al naufragio, y viceversa}

El naufragio del joven Daniel es una composición de corte dramático organizada de manera piramidal a partir del personaje principal de la tela: Elisa Bravo. A punto de desfallecer, la mujer se encuentra rodeada por un grupo de indios; la expresión de su rostro y el debilitamiento de su cuerpo contrastan, sin embargo, con la firmeza con la que sostiene a su hijo. Sin señales de socorro a la vista - en el fondo de la tela un barco está a punto de chocar contra un roquerío mientras a la distancia otro grupo de indios se acerca - el destino de Elisa Bravo está sellado. Los pies de un cuerpo en la orilla del mar, en la esquina inferior izquierda de la tela, es la prueba más evidente de la proximidad de la muerte. La composición se organiza a partir de contrapuntos raciales, de conducta y de género. Si consideramos el tema de la obra y las "convenciones" narrativas a las que este responde - una mujer sola, la única sobreviviente de un naufragio, "encontrada" por un grupo de indígenas - los Mapuche deberían haber sido representados de forma más violenta, dando indicios del destino de la mujer al interior de la narrativa proyectada por el artista7. Ahora bien, el carácter "salvaje" de los Mapuche no depende tanto de la caracterización hecha por el artista como de la actitud de Elisa Bravo hacia ellos. Incluso se podría argumentar que los Mapuche han sido sutilmente "disminuidos"; Monvoisin los ha retratado como "otros" ridículos y curiosos8. En vez de diestros guerreros, Monvoisin ha pintado personajes brutos e infantilizados, distanciados cultural, intelectual, social y políticamente de la "civilización". Su "atraso" y sus acciones pseudo-infantiles se visualizan a partir de la intensa curiosidad con la que examinan a Elisa Bravo.

Existe, sin embargo, un personaje que difiere del resto y que establece una peculiar relación con Elisa Bravo: la única mujer Mapuche presente en la tela, situada a su derecha. Mientras la atención de los indígenas se centra en el cuerpo de la mujer blanca, la india la observa detenidamente mientras agarra con fuerza la pierna del niño chileno, prestándole más atención que a su propio hijo. La presencia de niños - chilenos y Mapuche - y el rol que ellos tienen al interior de la composición le otorgan una dimensión distinta al carácter erótico usualmente atribuido a este díptico al interior del repertorio de la cautiva. Esta interacción revela y hace evidente una dinámica significativa en relación a los procesos de mestizaje: la apropiación de niños criollos. El detalle del pecho desnudo de la mujer Mapuche no solo erotiza la representación de lo indígena, sino que también se convierte en un símbolo del reemplazo del sustento y la tutela occidental. Capturada por los Mapuche, por otro lado, Elisa Bravo se transforma 
en una figura que habita el pasaje entre lo civilizado y lo no-civilizado; su cuerpo se ha convertido en una metonimia de "Chile".

Como había comentado anteriormente, Monvoisin basó sus pinturas en un evento real ocurrido en los meses de invierno del año 1849. El incidente y los ecos del mismo en las tertulias y salones de la clase alta chilena, a partir de su difusión en la prensa, coincidió con la segunda estadía de Monvoisin en Chile. Debido al impacto del episodio y la manera en que este fue tratado en la prensa - y si consideramos el estatus social de las relaciones del artista en el país - es improbable considerar que el artista no haya conocido los detalles de este affaire.

11 Los hechos son los siguientes: entre los últimos días de julio y los primeros días de agosto de 1849, el bergantín Joven Daniel, un barco de carga que estaba cubriendo la ruta Valparaíso-Valdivia, naufragó cerca de su destino final, a la altura de la costa de Toltén. Los pasajeros no eran muchos; además de la tripulación la lista oficial incluía a no más de veinte personas. Entre ellos, Juan Bañados, su esposa, Elisa Bravo, su hijo recién nacido y otras dos mujeres - más tarde identificadas como la madre de Bañados y la nodriza del niño. De acuerdo al posterior relato de Benjamín Vicuña Mackenna, publicado en 1884 y basado en una investigación militar comisionada por el gobierno chileno, tanto la tripulación como los pasajeros habrían muerto en el naufragio (VICUÑA MACKENNA, 1884). Rumores locales al momento de la tragedia y repetidos a través de la prensa en las principales ciudades del centro y sur de Chile contaron, sin embargo, una historia diferente: una historia de drama, violencia y muerte que introdujo a los Mapuche como los actores clave en una tragedia que los presentaba como un grupo de salvajes perpetuando prácticas sangrientas que atentaban contra el orden social de la república (LA TRIBUNA, 1849, p. 5).

Todo comenzó con un rumor. Los pasajeros habrían sobrevivido al naufragio y habrían recibido asistencia para salvar sus pertenencias y parte del cargamento del barco gracias a la ayuda de un grupo Mapuche de las cercanías de Puancho, cerca de Toltén. Premiados con un barril de brandy, los Mapuche habrían vuelto a su pueblo a disfrutar el regalo. El alcohol, sin embargo, habría prendido su "naturaleza violenta" y los habría predispuesto a atacar al grupo de chilenos. Después de matar a todos los hombres habrían violados a las mujeres y, con posterioridad, las habrían empalado aun vivas. El único sobreviviente habría sido un niño, el que habría sido posteriormente estrangulado por Curín, el cacique del grupo. Para no dejar huellas de sus actos, Curín y sus hombres habrían enterrado los cuerpos y llevado el cargamento al pueblo. La historia fue comentada - primero en el área de Puancho y después en la ciudad de Valdivia - por Porma, un Mapuche del área. ¿Cómo se habría enterado de la historia? Una machi, la curandera Catalina, le habría dicho que ella habría escuchado a Curín y a los otros Mapuche planeando el ataque mientras tomaban brandy. Ella le habría asegurado a Porma haber visto sangre en las ropas del grupo Mapuche y habría visto parte del cargamento en la ruca de Curín. Catalina le habría comentado a Porma esta historia para vengarse de los malos tratos que recibía por parte del cacique. Aun cuando tanto Porma como Catalina se retractaron de sus dichos al ser interrogados por los militares a cargo de la investigación, el rumor estimuló la animadversión de la sociedad chilena, que consideró plausible la historia presentada en la prensa. La desaparición de los cuerpos - el mar nunca los devolvió - contribuyó a la creencia generalizada de que los Mapuche los habían enterrado después de los asesinatos. 

lectores, que el gobierno del Presidente Manuel Bulnes fue presionado para abrir una investigación militar que presentara ante la ley chilena los hechos delictuales de los Mapuche y que sirviera de excusa para una posterior represión del Estado chileno. Las repercusiones de estos hechos continuaron hasta fines de 1849 en diversos medios de prensa. Durante ese periodo, editoriales y reportajes comentaron extensamente las fallas del Estado chileno en relación al "conflicto" Mapuche al sur de la Frontera. Fuera desde una perspectiva pacifista -proponiendo fundaciones de ciudades y colonias - o desde una posición violenta -proclamando la guerra y la erradicación de la población indígena - la opinión generalizada apoyaba la intervención del Estado chileno en tierras Mapuche. Bajo el nombre de la "Ocupación de la Araucanía", la intervención militar del estado finalmente comenzó, de manera programática, en 1861. El naufragio del Joven Daniel, ya fijado en el recuerdo de la sociedad chilena, fue constantemente evocado como un poderoso ejemplo de lo que podría volver a suceder si el Estado chileno no controlaba a los Mapuche. Y las pinturas de Monvoisin, realizadas dos años antes del comienzo de la intervención militar, fueron entonces asociadas a este evento. El ejemplo más paradigmático sobre esta cuestión es la presentación de la "Provincia de Arauco" en el Chile Ilustrado (1872) de Recaredo Tornero, una guía descriptiva de Chile, sus territorios y su gente, un libro de alta circulación y lectura en la época. Al interior del capítulo sobre Arauco (la Araucanía), el autor hace una división entre el "territorio conquistado" y el "territorio indígena". En esta última parte, el texto termina recordando el naufragio del Joven Daniel y presentado reproducciones de las obras de Monvoisin. La "horrible catástrofe", como la llama el autor, vincula simbólicamente las obras con los hechos "reales" basados, como es de esperar, en los rumores de Catalina y Porma.

No se conocen estudios previos o ayuda-memorias visuales o escritas de El naufragio del joven Daniel que permitan dar una idea acerca de las impresiones contemporáneas de Monvoisin con respecto al tema. Se podría inferir que además de las discusiones entre el artista y sus amigos y conocidos al interior del espacio del salón, el tema fue dejado de lado por el artista mientras se avocaba al retrato y a un grupo limitado de comisiones especiales basadas en escenas de género e históricas relacionadas a las figuras del libertador Bernardo O'Higgins y el cacique Caupolicán. De la misma manera, no existen registros que permitan dilucidar las razones por las cuales Monvoisin decidió pintar este tema; no se sabe si estaba siguiendo de manera atenta los asuntos políticos y militares de Chile desde París, o si más bien estaba diseñando una estrategia para atraer atención sobre su figura en el contexto del salón de París después de una larga ausencia. Lo que sí se sabe es que en algún momento después de su vuelta a París en 1859, Monvoisin comenzó a pintar El naufragio del joven Daniel. Después de un lapso de diez años el artista produjo una interpretación libre del episodio - interpretación que, en cualquier caso, estaba más en línea con las trágicas elaboraciones creadas en Chile alrededor de la figura de Elisa Bravo al interior del tropo de la cautiva.

Como ya había sido sugerido previamente, el artista creo la imagen de Elisa Bravo a partir del tema de la cautiva, tema que había hecho su emergencia durante la colonia a partir de crónicas que relataban la interacción de hombres y mujeres españoles en territorios indígenas. Durante el siglo XIX el tema mantuvo vigencia y circuló a través de dibujos, grabados, poesía y literatura. El poema La cautiva (1837) del argentino Esteban Echeverría inauguró un nuevo interés por el tema, esta vez en un contexto 
republicano. En términos visuales, la iconografía de la cautiva se basaba en la interacción entre indios y mujeres criollas/blancas, como es posible observar en El rapto de doña Trinidad Salcedo (1835) de Johann Moritz Rugendas, obra que discutiré más adelante. Representando el momento de la captura (haciendo eco de la larga tradición del rapto en la pintura occidental) o en cautiverio (dando cuenta del repertorio asociado al harem al interior de la pintura orientalista), estos encuentros presentaban a mujeres subordinadas y objetivadas; el indio, por otro lado, era comúnmente representado como un "otro" fuerte y bravo que amenazaba simbólica y materialmente la instalación y desarrollo de la cultura occidental. Curiosamente, la inclusión de individuos blancos/criollos en gran parte del repertorio de la cautiva estaba relacionado exclusivamente al momento de la captura. El hombre blanco, como tal, no es singularizado al interior del tropo; el punto de vista masculino (criollo, blanco) se perfila a partir de un fuera de cuadro que determina, de esta manera, la lectura del tema.

Inspirados en eventos reales donde mujeres jóvenes eran indistintamente secuestradas por mestizos o indígenas, artistas y escritores rápidamente identificaron al indígena como el único perpetrador de estos crímenes. Este significativo desplazamiento puede ser comprendido en relación al lugar que el indio, y específicamente el Mapuche, ocupaba en el imaginario de intelectuales, escritores y artistas chilenos y argentinos. Simbólicamente, el rapto de la mujer significaba el paso de la civilización a la barbarie, de los centros urbanos a la vida salvaje, y de una ciudadanía ilustrada a un pueblo indio/mestizo e inculto. Revelaba, también, el frágil orden de la sociedades americanas durante el proceso de descolonización. El indio, que para las elites encarnaba todos los vicios y peligros de las nuevas repúblicas, era una amenaza interna. La oposición entre civilización y barbarie fue célebremente cristalizada por Domingo Faustino Sarmiento (1811-1888) en Facundo: civilización o barbarie (1845), libro publicado en Chile durante el exilio de Sarmiento debido a la dictadura de Juan Manuel de Rosas (1793-1877). Aun cuando Sarmiento organizó sus ideas en torno a la figura del gaucho, ellas sentaron las bases para una reflexión intelectual y política acerca de los conceptos contenidos en el título de la obra. Como es de esperar, el tropo de la cautiva fue influenciado por la contribución ideológica de Sarmiento en la definición de los estados sudamericanos en relación a los enemigos internos del orden republicano. Fueran indios o gauchos, el estado debía combatir a sus enemigos internos.

La mujer, en este contexto, hacía posible el paso de la civilización a la barbarie debido a su "doble naturaleza": como figuras claves del orden republicano - a su cargo estaba el asegurar la existencia de la familia, el corazón de la cultura occidental - la mujer era considerada al mismo tiempo como una criatura que podía ser corrompida fácilmente debido a su carácter débil e irracional. Bajo la custodia de sus padres, hermanos y maridos, o de sus captores, la mujer era definida - como de costumbre - a partir de sus relaciones con otros hombres.

18 Aun cuando en el caso chileno no existen registros acerca del lugar que el repertorio de la cautiva tuvo al interior de colecciones privadas (si es que ellas efectivamente existieron), no sería equivocado inferir que estas imágenes eran consumidas de manera problemática. Si bien el público objetivo de estas imágenes eran hombres ilustrados americanos o extranjeros, estas imágenes también transmitían un mensaje para el género femenino. Si para un público masculino las cautivas eran fantasías eróticas que, al mismo tiempo, invocaban los peores temores que atentaban en contra de la 
civilización a través de la penetración de grupos bárbaros en el centro de la familia - la mujer -, para el género femenino estas imágenes eran un claro y desgraciado ejemplo de qué podía ocurrir si se alteraba la seguridad propuesta y mantenida por el orden patriarcal. Si uno va un poco más allá, se podría argumentar que una pintura como $\mathrm{El}$ naufragio del joven Daniel - inscrita al interior de la iconografía de la cautiva - reforzaba sutilmente una doble agenda: una que abogaba por la dominación de los enemigos del estado mientras se mantenía bajo control el cuerpo femenino.

\section{En la Araucanía, el cautiverio}

Si El naufragio del joven Daniel presenta la primera interacción entre mujer e indios, Elisa Bravo Jaramillo de Bañados, mujer del cacique proyecta, refuerza y consuma el tropo de la cautiva. Entre el cautiverio y el mestizaje Elisa Bravo es presentada por Monvoisin como la encarnación de la indolencia y la melancolía (AMIGO, 2007). Trenzando su pelo según su interpretación de la tradición Mapuche, adaptando su vestido al ambiente indígena y con el pecho al descubierto, Elisa Bravo no parece ser consciente de la mirada de los otros personajes de la composición sobre su cuerpo, la de las dos mujeres Mapuche sentadas detrás de ella y la del cacique de quién supuestamente está "casada" de acuerdo al título de la obra. Dialogando con su par, esta pintura sigue la misma estructura composicional de El naufragio del joven Daniel, a partir de un triángulo que encierra a todos los personajes dejando en el primer plano (e inclinada hacia la izquierda) a Elisa Bravo. Pero si en la primera obra ella sujeta fuertemente a su hijo, en esta obra su descendencia mestiza, producto de su unión con el cacique, es ignorada deliberadamente y no se dan pistas acerca del destino de sus hijos chilenos. Con la piel visiblemente más oscura, los niños mestizos no pertenecen ni a Elisa Bravo ni a los Mapuche.

Aun cuando el artista no terminó esta pintura (al compararla con El naufragio del Joven Daniel podemos dar cuenta de su carácter incompleto, cuestión que se percibe especialmente en el segundo plano y en el fondo), la obra ofrece suficiente información visual como para dar una idea acerca de la estrategia composicional del artista. A diferencia de El naufragio del Joven Daniel, Monvoisin ha diferenciado claramente el primer plano - el de la mujer blanca/criolla junto a sus hijos mestizos - del segundo - el de los Mapuche. Sin embargo, esta no es la única diferencia introducida por el artista en esta pintura. De manera significativa, ha combinado esta división espacial y composicional con una alteración de los roles "culturales" de los personajes, sugiriendo un contrapunto simbólico y, a la vez, paradójico.

21 Si partimos de la base de que Elisa Bravo está viviendo, en esta segunda pintura, entre los Mapuche, es desconcertante, por ejemplo, cómo el artista ha decidido describir tanto el espacio en el cual se inscriben los personajes como la única figura masculina de la obra. En medio de un bosque, una cabaña de madera domina el espacio y el cacique ha sido representado a su lado. La inclusión de la cabaña y la ropa del cacique problematiza la comprensión de Monvoisin de los Mapuche: en vez de representar tolderías (un conjunto de rucas, la vivienda básica Mapuche) ha pintado una choza; y en vez de representar a un jefe Mapuche, ha pintado a un campesino. Si el artista quería reforzar el carácter endémico de los Mapuche, su estrategia visual es confusa. Esta confusión podría explicarse argumentando que el artista no tenía un conocimiento etnográfico de los Mapuche. Si, por otra parte, consideramos que Monvoisin estaba 
optando por la descripción visual de un espacio mestizo, espacio que reforzaría los procesos de mestizaje implícitos en la composición, podríamos comprender su opción por representar una construcción de corte "occidental". En cualquier caso, sin embargo, la choza altera la lectura del tema, especialmente cuando consideramos cómo el artista ha presentado a los Mapuche y a Elisa Bravo en relación a ellos. Introducido como un campesino, ni su ropa ni su actitud lo "revelan" como un jefe indígena; tampoco existe ninguna conexión que nos permita establecer un vínculo entre este personaje y los Mapuche de El naufragio. Su posición en la pintura imposibilita la lectura del personaje a partir de un rol activo en la composición en términos de género y relaciones de poder.

A diferencia del cacique, las mujeres Mapuche han sido caracterizadas de forma más apropiada, proponiendo un interesante contrapunto entre "el" Mapuche "occidentalizado" y las mujeres "tradicionales". Totalmente cubiertas y sentadas de manera pasiva en un espacio intermedio entre el cacique y Elisa Bravo, su apariencia se encuentra en línea con los registros visuales que existen sobre la mujer Mapuche (BÁEZ, MASON, 2006). Este aspecto, sin embargo, deja a la otra tela en una posición peculiar, porque lo que observamos en el díptico es, finalmente, una inversión del rol de la "mujer occidental". En otras palabras, la forma en que el género ha sido representado en el naufragio se invierte en Elisa Bravo... Si en la primera pintura la mujer es presentada como una virgen sacrificial, en la segunda no solo ha sido presentada como una figura melancólica; también ha sido representada, de acuerdo a las convenciones sociales de la época, a partir de una moral ambigua. ¿Por qué? Porque Monvoisin también ha hecho eco, a través del uso de la iconografía de la melancolía, del mismo lenguaje corporal usado por la pintura orientalista para representar odaliscas. Elisa Bravo ha reemplazado simbólicamente, entonces, a la "exóticamente erótica" mujer Mapuche de pecho descubierto de El naufragio del joven Daniel.

Esta inversión se encuentra en sintonía con las experiencias formativas del artista después de su paso por la École des Beaux Arts y el taller de Pierre-Narcisse Guérin durante los primeros años del siglo XIX. Después de una residencia en Italia entre 1822 y 1824, Monvoisin volvió a París para dedicarse profesionalmente a la pintura a través de la creación de un círculo de clientes, de la participación en salones, y la reproducción y difusión de su obra a través de grabados ${ }^{10}$. Décadas antes de su viaje a América, especialmente entre las décadas de 1820 y 1830, Monvoisin había sido testigo del desarrollo del orientalismo en el milieu artístico francés. Más conservador y convencional que sus pares, el artista estuvo atento a las diversas formas en que el orientalismo permeó el arte y la literatura, especialmente en el trabajo de Juan Auguste Dominique Ingres, Horace Vernet, Ary Scheffer, Théodore Géricault y Eugène Delacroix (estos últimos tres artistas habían sido compañeros de Monvoisin en el taller de Guérin) y en la obra literaria de Victor Hugo y Alexandre Dumas. Como muchos otros artistas de su época, Monvoisin también experimentó dentro de los amplios márgenes dados por el orientalismo. Una de sus pinturas más conocidas de la década de 1830, por ejemplo, fue Alí Pashá, obra exhibida en el Salón de 1833. La pintura era una fantasía de corte dramático basada en Ali Pasha de Janina, un famoso gobernante otomano albanés que había muerto en 1822 y que era conocido por su brutalidad y crueldad hacia sus súbditos y enemigos. Retratando a Ali Pasha antes de su muerte y con su favorita del harén a sus pies, Monvoisin no solo estaba haciendo eco a obras como La muerte de Sardanapalo (1827) de Delacroix; también estaba instalando un motivo que posteriormente caracterizaría a su obra: la representación de hombres dominantes y 
mujeres sometidas, del que Elisa Bravo es un eco ya más bien tardío. Esta pintura, que fue uno de sus escasos (y relativos) éxitos en el salón de París, fue mucho más significativa en Chile y Sudamérica. La figura del tirano fue la base, por ejemplo, de la construcción del personaje de Facundo de Domingo Faustino Sarmiento en Civilización o Barbarie.

La caracterización de Elisa Bravo, además de estar iconográficamente en línea con la representación de odaliscas, también apelaba a la doble consciencia de la sociedad chilena de la época. De acuerdo a las convenciones sociales y de género del periodo, la "civilización" estaba prohibida para cualquier cautiva incluso si ella llegase a ser rescatada - la mejor perspectiva para cualquier mujer en esa condición era morir en cautiverio o pasar sus días encerrada en un convento tras deshonrarse a sí misma y a su familia. En otras palabras, la cautiva no podía rehabilitarse de su paso por lo "salvaje" pues su corrupción era irremediable. Debido a la "debilidad" de su género, Elisa Bravo ha abandonado, entonces, su antigua modestia; su contacto con los Mapuche la ha hecho abandonar su educación, delicadeza y cortesía. Esta doble conciencia puede ser explicada con un ejemplo temprano: una carta escrita en 1837 por Carmen Arriagada (1807-1888) al pintor bávaro Johann Moritz Rugendas (DIENER, 1997). Hacia esa fecha, Rugendas estaba profundamente interesado en la figura de la cautiva. Su fascinación por el tema puede haber sido impulsado por la tradición oral y escrita del sur de Chile y Argentina y, de manera más específica, por el poema épico de Esteban Echeverría, $L a$ cautiva. Respondiendo a una pregunta de Rugendas, Carmen Arriagada le escribía al pintor:

Sobre la pregunta que Ud. me hace de si conozco algún apellido de personas que se hayan robado los Indios. Hacen algunos 8 años que se llevaron de las cercanías de este pueblo una Seta Salcedo y de Chillán dos Setas hijas de una Sa Carrasco (...). Quedan, pues, a su disposición, estas tres personas... (PINOCHET DE LA BARRA, 1989, p. 96)

Lo interesante de este pequeño fragmento radica, por una parte, en la forma simple y directa con la que Arriagada comunica el destino de esas jóvenes - sus nombres, en otras palabras, su identidad "pública" asociada al apellido de sus familias, estaba a la disposición del artista. Por otro lado, es interesante destacar la asunción de Carmen Arriagada en relación a la identidad de los captores (la evidencia ha demostrado que al menos Trinidad Salcedo fue raptada por los hermanos Pincheira, un grupo de forajidos que apoyaban a la corona española (DEL VALLE, 2006, p. 155; CONTADOR, 1998). Para Arriagada, la objetivación de estas mujeres "corruptas" era tan obvia como la identidad de los captores como indios Mapuche. Como es de esperar, ambas ideas se fueron naturalizado con el tiempo. Fuera del orden diseñado por la sociedad civil, la única posibilidad de existencia para estas mujeres era, de acuerdo a Arriagada, su transformación en motivos pictóricos.

Aun cuando Rugendas produjo un ciclo de veinticinco pinturas sobre el tema, además de varias otras obras relacionadas al tema de la cautiva, todas realizadas entre la década de 1830 y la de 1850, me gustaría llamar la atención sobre El rapto de doña Trinidad Salcedo, un ejemplo temprano de la iconografía de la cautiva en el contexto republicano. Combinando acciones de indios y forajidos, esta pintura se basa en la idea del malón: un grupo de indios a caballo arrasa con un pueblo destruyendo el área urbana y robando caballos, ganado y mujeres jóvenes. En el área central de la composición un indio lleva a Trinidad Salcedo, quien levanta sus brazos de manera desesperada en busca de ayuda; alrededor de ellos, la supremacía de los Mapuche es 
evidente. La relevancia de una obra como esta para los propósitos de este texto, reside en el destino final de una versión sutilmente distinta publicada en el Atlas de la historia física y política de Chile del naturalista francés afincado en Chile, Claude Gay (1800-1873). Publicada en París en 1854, el atlas fue concebido como la visualización tanto del territorio y de los recursos naturales del país como del pueblo de Chile. Destinada a dar una forma "visual" a la nueva república, los dos volúmenes del atlas eran parte de un proyecto de mayor envergadura desarrollado por Gay y comisionado en 1839 por Mariano Egaña (1793-1846), Ministro de Instrucción Pública.

Fig. 3 - Johann Moritz Rugendas. “Un malón,” litografía coloreada, en Claude Gay

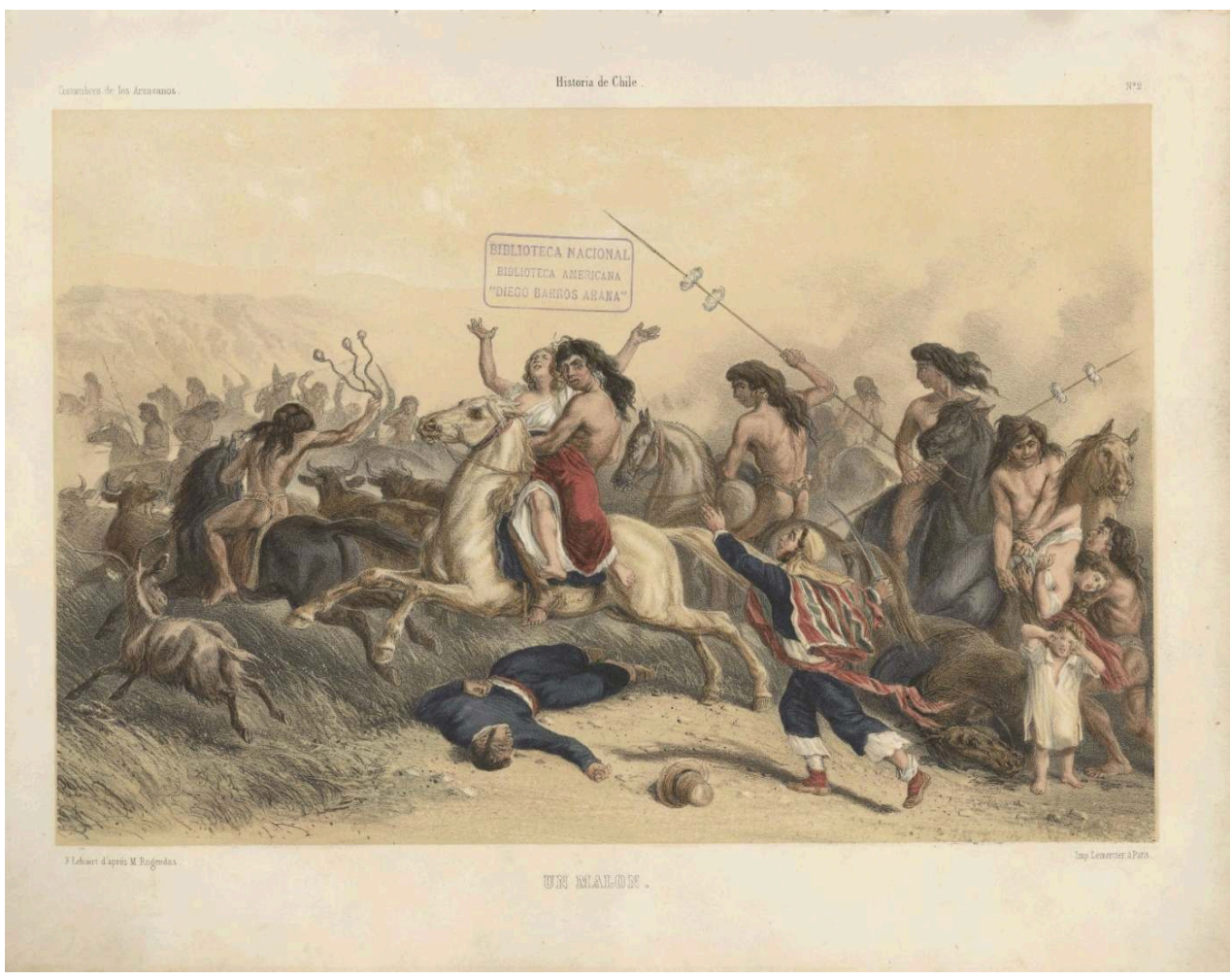

Atlas de la historia física y política de Chile, vols. 1. Paris: Imprenta de E. Thunot y Ca., 1854

Colección: Biblioteca Nacional, obra en dominio público.

La mayoría de las láminas del álbum fueron realizadas por Gay, pero Rugendas contribuyó con un buen número de imágenes; entre ellas, la lámina n.2: Un malón (fig. 3). En este grabado, El rapto de doña Trinidad Salcedo ha sido oficialmente transformado. Incluida en la sección de las Costumbres de los Araucanos, la imagen es inventariada como parte de un ejercicio etnográfico requerido por el gobierno de Chile. Los Mapuche son presentados como un grupo rebelde, "otro", pero que forma parte de la inclusiva república chilena.

Si consideramos la totalidad de las láminas del atlas, se hace necesario destacar que las imágenes que dan cuenta de la interacción Mapuche-chilena están exclusivamente relacionadas a la guerra. La primera es el malón. La segunda es el sketch histórico de Gay Parlamento de Ambrosio O'Higgins en Negrete -1793. Estas dos imágenes dan una idea del tono de la edición de Gay en relación a la comisión del gobierno: cuando los Mapuche no son representados bajo una mirada etnográfica, ellos son presentados como una amenaza al estado chileno. De hecho, se podría argumentar que la inclusión 
de Un malón en la edición de Gay fijó el tema y sus resonancias políticas en un particular marco de referencias: el de la ciencia y la representación nacional. Incluida en un conjunto de imágenes del país, junto a mapas, taxonomías de la flora y fauna e imágenes de tipos y costumbres que distinguían la alta de la baja cultura, el malón de Rugendas ganó verosimilitud. Aun cuando sería difícil precisar las rutas de circulación de otras imágenes de malones y cautivas, es difícil ignorar la visibilidad del malón de Rugendas al interior del atlas de Gay. A partir de la relevancia editorial del atlas y de sus rutas de circulación (de Francia a Chile y, en Chile, del puerto de Valparaíso a Santiago, La Serena, Copiapó, Concepción, Talca y otras ciudades relevantes), se podría proponer que Monvoisin tuvo la oportunidad de revisar este material gracias al tipo de relaciones que el artista tenía en Santiago y en el puerto, ya fuera durante su proceso de edición o ya como un set editado de láminas. Además, la llegada del atlas a Chile después de su proceso de edición e impresión en Francia -, coincide con un periodo de tiempo (alrededor de 1854) cuando Monvoisin estaba de hecho interesado en el estudio de los Mapuche mientras preparaba dos proyectos sobre el héroe Mapuche Caupolicán.

Rugendas y Monvoisin no eran figuras cercanas, pero como artistas viajando a través de América del sur, diseñaron rutas similares. Monvoisin estaba, de hecho, siguiendo las huellas de Rugendas ${ }^{11}$. David James, el biógrafo de Monvoisin, documentó un breve encuentro en Santiago en 1845 que podría haber motivado el viaje que el francés habría hecho posteriormente a Perú, siguiendo la recomendación de Rugendas (JAMES, 1989). En Chile, compartían el mismo círculo de relaciones. Entre ellos, escritores, intelectuales y políticos como el Presidente de Chile entre 1841 y 1851, el conservador Manuel Bulnes (1799-1866); Andrés Bello (1781-1865), estadista y fundador de la Universidad de Chile; el intelectual y futuro presidente de Argentina, Domingo Faustino Sarmiento, Claude Gay y Mariano Egaña, entre otros, asociados a las tertulias de Isidora Zegers (1803-1869), Carmen Arriagada y Enriqueta Pinto de Bulnes (1815-1904). Si bien el díptico de Elisa Bravo no tiene similitudes composicionales con El malón, me gustaría sugerir que la lámina de Rugendas - con su resonancia política y social enraizada en la definición de lo "indígena" y del comportamiento de género -, gravitó fuertemente alrededor de la concepción de las obras de Monvoisin, especialmente cuando consideramos la concepción del cuerpo de la mujer como un bien intercambiable y la transformación de su identidad en un tropo que permitía la visualización de luchas de poder al interior del Estado. Las palabras de Benjamín Vicuña Mackenna al referirse a la historia de Elisa Bravo son significativas al respecto, sobre todo al tener en cuenta que el subtexto de sus palabras alude a la expansión militar del Estado chileno, vinculando el tropo de la cautiva con la historia geopolítica de Chile:

Mas y aun pudiéndolo [su rescate] nosotros ya no lo desearíamos.- ¿Qué haria con su vida aquella infeliz señora? (...) Su prole habria de ser toda bárbara (...) Su belleza juvenil trocada en escarnio de senectud (...) Cambiando su dulce hablar en voces guturales; turbio el azul de sus ojos por los hielos o el fuego de la intemperie, convertidas en blanquecinas mechas su rubias y esplendente cabellera, encorbada, irritable, olvidada de la plegaria, convertida en idólatra y talvez, por el odio y la venganza en harpía, un cruel cautiverio de treinta y cinco años, edad que para una mujer bella es más de un siglo, su devolución a la vida de los cristianos sería para ella más que una dicha un sarcasmo (...). (VICUÑA MACKENNA, 1884, p. 525)

Si uno tiene presenta las observaciones de Carmen Arriagada y Benjamín Vicuña Mackenna, una vez "expuesta" a indígenas bárbaros la cautiva no puede recuperar su vida anterior. El gesto y la pose indiferente de Elisa Bravo en la pintura son pruebas de 
su corrupción. Paradójicamente, Elisa Bravo ha sido, al mismo tiempo, erotizada y transformada en una mujer poco atractiva para el hombre chileno.

Aun cuando la obra no se ajusta a los estándares de la representación decimonónica de la "mujer caída", Elisa Bravo... comparte la proyección de una superioridad moral y masculina en la comprensión del tema. Esta cuestión es aún más problemática cuando consideramos el título completo de la obra: "Elisa Bravo Jaramillo de Bañados, mujer del cacique". A través del título podemos agregar un problema que cruza tanto el género como la formación de clases: la mujer no solo ha sido identificada por los apellidos de sus progenitores; también ha sido agregado el "de Bañados", apellido de su esposo, indicando su estatus de mujer casada. Elisa Bravo ha sido, entonces, relacionada a tres apellidos, el de su padre, el de su madre y el de su esposo, enraizándola en un contexto genealógico, social e histórico específico. Estos tres apellidos, es decir, estos tres indicadores sociales, hacen aun más paradójico su estado actual como "mujer del cacique". Ya no es más una "señora", sus nombres no corresponden con su actual situación: una desventurada. Entregada a "lo salvaje", Elisa Bravo es, para el artista metropolitano y para el hombre chileno, una "mujer caída". Pero si en la pintura de género europea la "mujer caída" podía volver a su vida pasada, rechazando sus antiguos vicios "a través de la penitencia y la posterior reintegración en el seno de la familia", lo que cambia en este caso es la imposible reincorporación de la cautiva al centro de la vida social occidental (NOCHLIN, 1989, p. 61).

Fig. 4 - Raymond Monvoisin, Enriqueta Pinto de Bulnes, ca. 1843, óleo sobre tela, 120 x $100 \mathrm{~cm}$

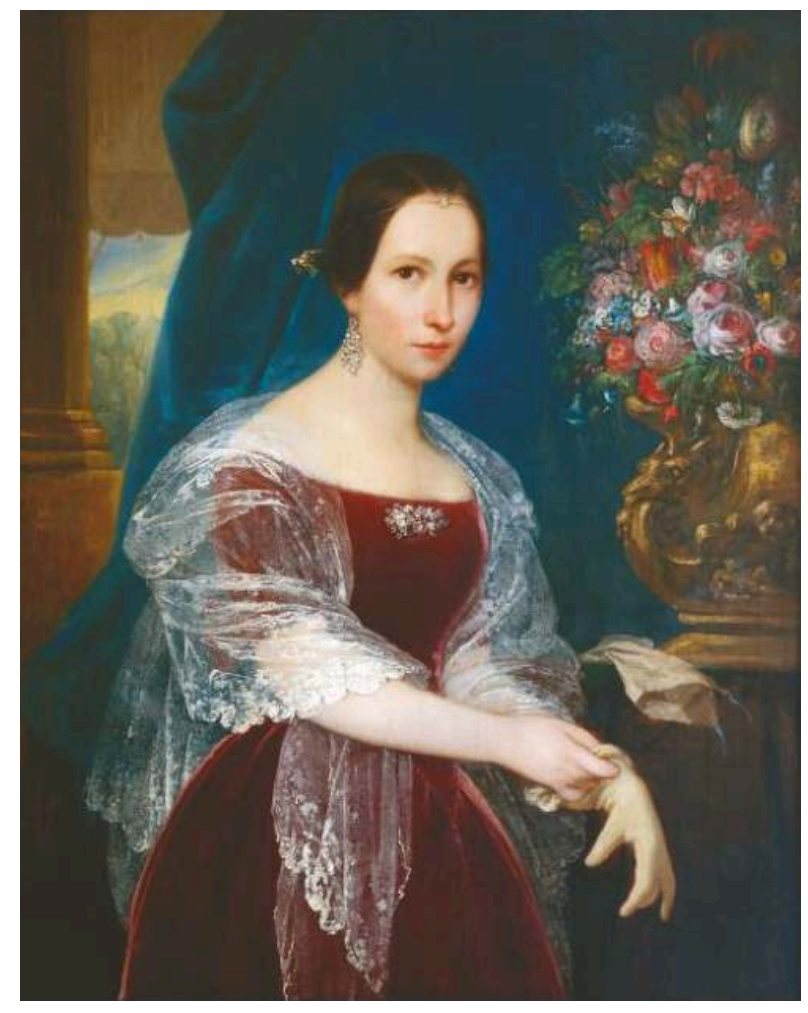

Colección privada. Fotografía: ORIGO Ediciones

Al contrario, mujeres de clase alta eran representadas de forma muy diferente. Cuando pintaba a señoras de la clase alta chilena, Monvoisin seguía las convenciones sociales y morales del género del retrato. En el retrato de Enriqueta Pinto de Bulnes (ca. 1843, 
fig. 4), por ejemplo, el artista ha representado a la mujer del Presidente de Chile, Manuel Bulnes, en pose tres cuartos, vistiendo un elegante traje importado de Europa y mirando de manera recatada al observador. Levantando la mirada mientras se calza los guantes, sus mejillas encendidas no son solo evidencia de su juventud; también, de su candor y modestia. Como es de esperar, utiliza el apellido de su marido y de esa manera es señalada, entonces, como su consorte, la primera dama. Al estar casada tiene la posibilidad de aparecer ante el espectador dando cuenta de las virtudes de una mujer bien educada. Esta aparición, en todo caso, estaba limitada al espacio doméstico y privado. Cuando comparamos el retrato de Enriqueta Pinto de Bulnes con el de su marido, el Presidente de Chile, es posible tener una mayor comprensión de las dinámicas de género de la clase dirigente a mediados del siglo XIX. También pintado por Monvoisin en 1843, el retrato de cuerpo completo de Bulnes ha sido realizado a la grand manner. Pintado como un militar, Bulnes encarna, a través de su pose, mirada, traje, y el fondo rojo y dorado de la tela, todos los atributos del poder. El retrato de Manuel Bulnes es oficial: pertenece a la historia y a Chile. De hecho, esta pintura se encuentra hoy en la galería de retratos del Museo Histórico Nacional. El retrato de Enriqueta Pinto de Bulnes, por otro lado, más modesto en dimensiones y técnica, fue mantenido en el espacio doméstico para ser admirado por la familia y sus más cercanos. Hasta el día de hoy, el retrato de la dama se encuentra en el salón de la familia.

Considerando las ideas presentadas a lo largo de este texto, me gustaría sugerir que el díptico sobre Elisa Bravo está permeado por las dinámicas del imperialismo. Es más, me gustaría sugerir que el pintor metropolitano no ve a Chile como una República, sino como un espacio colonial - aun cuando Chile sea un estado independiente actuando sobre el pueblo Mapuche de manera expansionista. Comprendiendo el cuerpo de Elisa Bravo como un cuerpo tomado por las dinámicas del colonialismo - y de manera independiente de su estatus previo al interior de la sociedad cultivada chilenaMonvoisin proyectó fantasías masculinas occidentales en relación a mujeres "nooccidentales". Sea para el público (masculino) chileno o desde la perspectiva del artista, el cuerpo de Elisa Bravo contiene (y es reducido a) prejuicios masculinos y a una exacerbada desigualdad de género. Para reforzar esta última idea, me gustaría terminar este texto comparando la forma en que Monvoisin ha pintado a Elisa Bravo con In Memoriam, una obra pintada por Sir Joseph Noel Paton y exhibida en 1858, un año antes de que Monvoisin expusiera su díptico en el salón de París, en la exposición anual de la Royal Academy en Inglaterra. Largamente discutida por Linda Nochlin, esta obra ofrece un interesante contrapunto en relación a los diferentes modos de visualización del cuerpo femenino (NOCHLIN, 1989). Nochlin comenta que "existen al menos dos discursos articulados en esta imagen. Una es la abiertamente heroica historia de las damas británicas y sus hijos durante el motín de Sepoy; fortalecidas por la oración mientras esperan ser asaltadas por salvajes y presumiblemente lascivos nativos. El otro discurso, menos obvio, es patriarcal y definido por la clase a la que pertenecen las mujeres, discurso que estipula el apropiado comportamiento de una dama, y que implica que ninguna de ellas pondría en cuestión las características asociadas a su género, aun cuando las violentaran o aun en defensa de sus hijos" (NOCHLIN, 1989, p. 6). En las obras de Paton y Monvoisin se pueden observar dos episodios coloniales similares en el que mujeres están "a punto" de ser asaltadas por nativos. Independiente de que ambos artistas vean a la mujer como un ser débil y pasivo, lo que cambia de una obra a la otra es cómo esa pasividad y debilidad es expresada. Si en In Memoriam la mujer al centro de la composición está ensimismada al interior de las coordenadas de 
género de la moral victoriana, en Elisa Bravo la mujer no parece haber absorbido las lecciones de la moral y de comportamiento de género propios de la cultura occidental. Monvoisin incluso ha descartado fuentes literarias y pictóricas en donde la cautiva aparece rechazando indios, tratando desesperadamente de escapar, anhelando tristemente su vida pasada o refugiándose en la religión. De modo esquemático, Monvoisin ha orientalizado a Elisa Bravo, vinculando su figura a la representación de la odalisca. Entre medio de realidades coloniales, poderes imperiales, y sus experiencias en Sudamérica mediadas por su conocimiento del "cercano oriente" a través de la literatura de viajes, cuentos, arte y cultura visual, Monvoisin articuló, en el díptico de Elisa Bravo, el orientalismo europeo y el costumbrismo latinoamericano, dos géneros definidos en gran medida por la expansión imperial.

\section{BIBLIOGRAFÍA}

\section{Fuentes primarias}

El Araucano, Santiago, 1849.

El Comercio, Santiago, 1849.

La Tribuna, Santiago, 1849.

El Progreso, Santiago, 1849.

Legación de Chile en Francia y Gran Bretaña, vol. 4 (1842-1846), Archivo Nacional.

RICHON BRUNET, Ricardo (1909-1910), “Conversaciones sobre arte”, Revista Selecta, Santiago.

Salon de 1859. Explication des ouvrages de peinture, sculpture, gravure, lithographie et architecture... Paris, Imprimeurs des Musées Impériaux, 1859.

SARMIENTO, Domingo Faustino (1845), Facundo: civilización o barbarie, Santiago, Imprenta del Progreso.

TORNERO, Recaredo (1872), Chile ilustrado, guía descriptive del territorio de Chile, Valparaíso, Librerias i Ajencias del Mercurio.

VICUÑA MACKENNA, Benjamín (1884), "Elisa Bravo o sea el misterio de su vida, de su cautividad y de su muerte, con las consecuencias políticas y públicas que la última tuvo para Chile”, en Revista de Artes y Letras, tomo I, Santiago, Julio 1884, pp. 493-529.

VICUÑA MACKENNA, Benjamín (1989 [1876]), Los girondinos chilenos, Santiago,Universitaria.

\section{Fuentes secundarias}

AMIGO, Roberto (2007), “Beduinos en la pampa. Apuntes sobre la imagen del gaucho y el orientalismo en los pintores franceses", en Historia y sociedad, n. 13, Medellín, Universidad Nacional de Colombia, Facultad de Ciencias Humanas y Económicas. 
BÁEZ, Christian, \& Peter Mason (2006), Zoológicos humanos. Fotografías de fueguinos y Mapuche en el Jardin d'Acclimatation de Paris, siglo XIX, Santiago, Pehuén.

BARON, Beth (2005), Egypt as a Woman: Nationalism, Gender and Politics, Berkeley: University of California Press, 2005.

BENGOA, José (2000), Historia del pueblo Mapuche (siglo XIX y XX), Santiago, LOM.

BOHRER, Frederick (2003), Orientalism and Visual Culture Imagining Mesopotamia in Nineteenth-Century Europe, Cambridge, Cambridge University Press.

CASTRO, Marcela, et al. (1994), 'Fronteras, mujeres y caballos', en Lea Fletcher (ed.), Mujeres y Cultura en la Argentina del siglo XIX, Buenos Aires, Feminaria Editora, pp. 147-157.

CONTADOR, Ana María (1998). Los Pincheira. Un caso de bandidaje social Chile 1817-1832, Bravo y Allende Editores, Santiago.

CUSAK, Tricia \& SIGHLE BHREATHNACH-LYNCH (eds.). Art, Nation, and Gender: Ethnic Landscapes, Myths, and Mother Figures, 2003, Aldershot, Ashgate Publishing.

DEL VALLE TABATT, Francisca (2006) “El repertorio visual de las cautivas...”, Santiago, RIL editores.

De la MAZA, Josefina (2011), "From Metropolitan Decadence to Provincial Success. Raymond Q. Monvoisin and the Chilean Post-Independent Elite of the 1840s", en Ana María León y Alla Vronskaya (eds.), In the Distance *Research-in-Progress 2010, Cambridge, MA, MIT Department of Architecture, pp. 36-39.

De la MAZA, Josefina (2013), Contesting Nationalism: Mamarrachos, Slave-Pieces, and "Masterpieces" in Chilean Nineteenth-Century Painting, Tesis Doctoral, Department of Art History and Criticism, SUNY Stony Brook, NY.

DIENER, Pablo (1997), Rugendas 1802-1858, Ausburg: Instituto Goethe San Pablo.

IGLESIA, Cristina (2000), 'La mujer cautiva: cuerpo, mito y frontera', Georges Duby y Michelle Perrot (eds.), Historia de las Mujeres en Occidente, Madrid, Taurus, pp. 583-597.

IVELIC, Milan \& Gaspar Galaz (1981), La pintura en Chile. Desde la colonia hasta 1981, Valparaíso, Ediciones Universitarias de Valparaíso.

JAMES, David (1949), Monvoisin, Buenos Aires, Emecé.

LANDES, Joan B. (2001), Visualizing the Nation: Gender, Representation, and Revolution in Eighteenth-Century France, Ithaca, Cornell University Press.

MAYO, Carlos (1999), 'La frontera; cotidianeidad, vida privada e identidad', Fernando Devoto y Marta Madero (eds.), Historia de la Vida Privada en la Argentina. País antiguo. De la colonia a 1870, Buenos Aires, Taurus, pp. 85-105.

MALOSETTI, Laura (1994), Rapto de cautivas blancas..., Buenos Aires, Hipótesis y discusiones n.4, UBA.

MALOSETTI, Laura (2000), 'Mujeres en la frontera', Fernanda Gil Lozano, et. al., Historia de las mujeres en la Argentina, Buenos Aires: Taurus, vol. 1, pp. 87-109.

MENARD, André (2009), "Pudor y representación. La raza mapuche, la desnudez y el disfraz", Aisthesis n. 46: 15-38.

NOCHLIN, Linda (1989), Women, Art, and Power and Other Essays, New York, Harper and Row. 
PINOCHET de la BARRA, Oscar (1989), Carmen Arriagada cartas de una mujer apasionada, Santiago, Editorial Universitaria.

PEREIRA Salas, Eugenio (1992), Estudios sobre la historia del arte en Chile republicano, Santiago, Ediciones de la Universidad de Chile.

RAMASWAMY, Sumathi, (2008) 'Maps, Mother/Goddesses and Martyrdom in Modern India', Journal of Asian Studies 67, no. 3 (2008): 819-53.

ROMERA, Antonio (1950), Razón y poesía de la pintura, Santiago, Ediciones Nuevo Extremo.

ROMERA, Antonio (1951), Historia de la pintura chilena, Santiago, Editorial del Pacífico.

ROSENTHAL, Donald A. (1982), Orientalism. The Near East in French Painting 1800-1880, Rochester, Memorial Art Gallery of the University of Rochester.

Rugendas: América de punta a cabo (1992), Santiago, Aleda.

SALAS, Alberto (2000), 'El mestizaje en la conquista de América', Georges Duby y Michelle Perrot (eds.), Historia de las Mujeres en Occidente, Madrid, Taurus, pp. 553-582.

VILLALOBOS, Sergio (1995), Vida fronteriza en la Araucanía..., Santiago, Editorial Universitaria.

\section{NOTAS}

1. Para un detallado reporte de la vida del artista ver Monvoisin, biografía escrita por David James (Buenos Aires: Emecé, 1949). A pesar del tono celebratorio y poco crítico del autor, el texto de James es clave para comprender la vida y obra del artista. Para reacciones contemporáneas a la llegada del artista francés a Chile, ver las reseñas del periódico El Progreso, durante los primeros meses del año 1843. Toda la información presentada sobre el artista se basa en la biografía de James o en mi propia investigación.

2. La mayoría de las historias del arte chilenas escritas durante el siglo XX coinciden en situar a Monvoisin como una figura clave en la diseminación del arte y gusto francés en Chile. Ver, por ejemplo, las "Conversaciones sobre arte" de Ricardo Richon Brunet en la Revista Selecta (Santiago, 1909-1910); la Historia de la pintura chilena de Antonio Romera (Santiago: Editorial del Pacífico, 1951) y La pintura en Chile. Desde la colonia hasta 1981 de Milan Ivelic y Gaspar Galaz (Valparaíso: Ediciones Universitarias de Valparaíso, 1981). Una visión interesante y diferente de este asunto se puede observar en Estudios sobre la historia del arte en Chile republicano de Eugenio Pereira Salas (Santiago, Ediciones de la Universidad de Chile, 1992). Sobre los "efectos" de la presencia de Monvoisin en Chile y para una crítica a las posturas anteriores ver Josefina de la Maza, "Once Upon a Time: The Monvoisin Effect and the Constitution of the Myth of Origin of Chilean Art", en Contesting Nationalism: Mamarrachos, Slave-Pieces, and "Masterpieces" in Chilean Nineteenth-Century Painting, Tesis Doctoral, Department of Art History and Criticism, SUNY Stony Brook, NY, 2013 (texto inédito).

3. Para un texto seminal sobre el tropo de la cautiva en el contexto americano, ver Laura Malosetti, Rapto de cautivas blancas... (Buenos Aires: Hipótesis y discusiones n.4, UBA, 1994).

4. Mapuche (mapu: tierra / che: gente). Los Mapuche viven en el sur de Chile y de Argentina. En el caso chileno, la principal zona Mapuche ha sido, históricamente, la de la Araucanía; región definida por los ríos Bío Bío y Toltén - los límites que dividían el territorio chileno del Mapuche era conocido como La Frontera. La militarización de la Araucanía se mantuvo durante el siglo XIX. Aun cuando el estado mantuvo relaciones amigables con algunos grupos Mapuche, nunca hubo un reconocimiento bilateral de "paz". En 1861, el Presidente José Joaquín Pérez comenzó la campaña de la "Ocupación de la Araucanía". Las consecuencias de esta campaña 
fueron catastróficas para el pueblo Mapuche: la desigualdad, discriminación y violencia generadas por las acciones del Estado de Chile son visibles hasta el día de hoy. El díptico de Elisa Bravo lidia con la representación de los Mapuche viviendo cerca del río Toltén. Para visiones opuestas y contemporáneas de los Mapuche, ver José Bengoa, Historia del pueblo Mapuche (siglo XIX y XX) (Santiago, LOM, 2000) y Sergio Villalobos, Vida fronteriza en la Araucanía... (Santiago: Editorial Universitaria, 1995)

5. Ver, al respecto, los documentos que se encuentran en la Legación de Chile en Francia y Gran Bretaña, vol. 4 (1842-1846), Archivo Nacional.

6. De la totalidad de este grupo de obras, Monvoisin exhibió en el Salón de París de 1859 los Dos esposos paraguayos (o Refugiados del Paraguay), el Caupolicán... y Elisa Bravo. Salon de 1859. Explication des ouvrages de peinture, sculpture, gravure, lithographie et architecture... (Paris, Imprimeurs des Musées Impériaux, 1859, p. 271).

7. La crónica más antigua y notable acerca del pueblo Mapuche es La Araucana (1569) de Alonso de Ercilla. Escrita desde la perspectiva de un soldado español durante el periodo de la conquista, el poema celebra la gallardía y belicosidad de los Mapuche.

8. Durante la primera mitad del siglo XIX una de las publicaciones más influyentes en la configuración de los Mapuche desde una perspectiva estatal fue el Atlas de la Historia Física y Política de Chile de Claude Gay, impreso en 1854 en París. Para estudios contemporáneos sobre el tema, ver: Christian Báez y Peter Mason, Zoológicos humanos. Fotografías de fueguinos y Mapuche en el Jardin d'Acclimatation de Paris, siglo XIX (Santiago: Pehuén, 2006) y André Menard, "Pudor y representación. La raza mapuche, la desnudez y el disfraz" (en Aisthesis no46, Santiago (2009): pp. 15-38).

9. Para mayores referencias sobre relaciones entre género, territorio y nación, ver las publicaciones de Joan B. Landes, Beth Baron, Sumathi Ramaswamy y Tricia Cusack y Sighle Bhreathnach-Lynch listadas en la bibliografía.

10. Es importante mencionar que la residencia de Monvoisin en Italia no estuvo sustentada por la obtención del Prix de Rome. Su maestro, Guérin, le consiguió una beca al asumir la dirección de la École en Roma.

11. Rugendas vivió en Chile entre 1834 y 1842 - ese año viajó a Perú y se quedó en el norte hasta 1845. Monvoisin llegó a Chile en 1843.

\section{RESÚMENES}

En 1859, después de años de viajar por Sudamérica y de un largo periodo en Chile, el artista francés Raymond Q Monvoisin (1790-1870) expuso en el salón parisino un grupo de obras que daban cuenta de sus "experiencias sudamericanas". Entre ellas, Monvoisin presentó un díptico conformado por "El naufragio del joven Daniel" y "Elisa Bravo Jaramillo de Bañados, mujer del cacique" (ambas de 1859). Situándose más allá de los acontecimientos reales que gatillaron la concepción del díptico, Monvoisin transformó un naufragio producido en las costas del sur de Chile en una ficción bárbara cuyos principales actores eran los Mapuche. Utilizando como punto de partida la iconografía de la "cautiva", un tema conocido y utilizado desde la época de la colonia, el díptico contribuyó a presentar a la Araucanía, zona Mapuche por excelencia, como una región indomable que debía ser conquistada y dominada por el estado chileno.

Este artículo analizará el díptico de Elisa Bravo a la luz de la representación de la mujer al interior de discursos coloniales y de expansión imperial, reconstruyendo el lugar de la mujer 
decimonónica entre redes artísticas y simbólicas, entre Chile y Sudamérica y entre Sudamérica y Europa.

\section{ÍNDICE}

Parole chiave: Monvoisin, cautivas, naufragio, Mapuche, mestizaje

\section{AUTOR}

JOSEFINA DE LA MAZA

Depto. de Arte, Universidad Alberto Hurtado Santiago, Chile josefinadlm[at]uahurtado.cl 